\title{
The Integrated Research of university Literature Teaching and the Modern Information Technology Resources
}

\author{
Yanfeng $\mathrm{Si}^{1, \mathrm{a}}$, Guangmiao $\mathrm{Xu}^{2, \mathrm{~b}}$, Chen Ping ${ }^{3, \mathrm{c}}$ \\ ${ }^{1}$ Department of Social science teaching, Xingtai University \\ Xingtai, 054001, China \\ 2 Department of Chinese language and Literature, Xingtai ,University \\ Xingtai, 054001, China \\ ${ }^{3}$ Department of Chinese language and Literature, Xingtai ,University \\ Xingtai, 054001, China \\ aemail: xgm0313@163.com, bemail:xgm0313@163.com, email:xgm0313@163.com
}

Keywords: university literature teaching, modern information technology, integration

\begin{abstract}
The modern information technology applied in university literature teaching, which has the incomparable advantage than traditional teaching method. The profound changes of the teaching method, teaching subject and teaching content are produced by the integrated process of information technology resources and the university literature teaching.
\end{abstract}

\section{Introduction}

Modern information technology resources include the application of computer hardware and software, network and communication technology and software developed tools and so on. With the popularization use of computer and network, people gradually use computer to produce, handle, exchange and spread the various forms of information. The wide use of the modern information technology all over the world, it not only influences the economic structure and the economic efficiency, and also produces the profound influence in the higher education.

\section{University Literature Teaching in the Integration of Modern Information Technology Changing the Subject Identity}

Teachers' multiple identities from lectures to the producers, directors and managers. In traditional teaching, the teachers as the people who are received the special education and train transferring the human scientific, cultural knowledge, skills to students and cultivate students the ideology, morality and aesthetic taste. They choose the classroom as medium. The mainly way is according to the word of mouth that is teaching. However, information age, the application of modern class technology let the teachers who don't only pass on knowledge anymore. The task of teachers is more showed in "guide". They should help students decide the studied aims suited individual need and practice. They create abundant teaching scenes to motivate students' intention in getting knowledge and skills, to cultivate healthy interests and shape virtual moral, to perfect character and mental. As for the rich network literature resources, in the process of preparing lessons, it should change single text teaching plan into electronic courseware. The university literature teachers may face the work to integrate a variety of resources of the writers or the pictures, audio and video of works. Those must need a teacher change into the producer or the presenter of this work. In class teaching, teachers should combine the traditional class teaching and electronic courseware. Teachers must be a director of organization in the classes. They should know how to divide the traditional class teaching and electronic courseware in the class time and space and how to combine them. Therefore, it can be more actively and dynamic adjusting the teaching layout. It can give students more studying help in personality. Teachers will be the management in the whole teaching process. 
Student's Multiple Identities from Receivers to the Audience. Today, the university education mainly faces the students of the generation after 90s. These so-called"new human being" were born in the forward of the reform and opening-up policy period. They grow up in the rise of information technology and don't experience the political and economic changes of that era. They are in the information environment all the time, therefore, their thoughts are more active than the previous generation. They are not only the prior experiencers but also the prophets for the information age. It makes that in class teaching mode, they prefer to receive images and the videos marked for the "visual culture" for them growing up with televisions and computers. In the teaching process of university, when let the aesthetic of literature space through the information technology developing into multilevel perspective, students can listen, see, sense, participate in and can as the multiple identities to cognize and appreciate the culture. For example, the teahouse of Lao She that can be read through papers and through teachers' guidance and analysis understood the work deeply. They can also through the information technology to broadcast Beijing people's art of typical show of teahouse to understand this kind of stage art form, even can organize students to perform this show. Therefore, in the combination of information technology in the class teaching, students change from the receivers to the multiple identities of audiences, spectators and participants. So for the generation after 90s who have the daring and open personalities, they like to accept new things and research new things. These multiple identities can let them gain more emotional experience, which fit their generation background and thinking mode.

\section{University Literature Teaching in the Integration of Modern Information Technology Resources Changing Teaching Content}

University Literature Teaching in the Integration of Modern Information Technology Resources changed more technical. Today, information technology is changing a lot. University teaching for the integration of modern information resources has not just changed from paper manuscripts to electronic manuscripts, realizing the teaching information that is no longer just about the popularity of electronic lesson plans, or from text into a PPT, but it let the latest information technology apply to the real teaching. Whether teaching courseware install or unload easily or response quickly, modify easily, run reliable or whether the technology of fast response, easy modification, reliable running. Whether the technology is stable and it has moderate speed and harmonious whole style. Whether is concise and beautiful of the layout. Whether has dubbing standard. Whether inspires the students' thinking and cultivates the students' innovative ability. As the expressers, processors, handlers and makers of the teaching courseware for the teaching content, teachers are in the dominant position. So in order to achieve true integration of modern information technology and the university teaching, the core is to strengthen the cultivation of teachers' information technology. It is not easy for many teachers to realize the true information technology in teaching content, because most of them teach by blackboards and chalks. Even though, the young teachers just graduated from universities, they know little about the FLSH, SCIENCE WORD and the website construction. In modern multimedia teaching of university, the main content and aim for the work of teachers' training is to improve the teachers' modern information technology skills. At the same time, it also should strengthen the coordination in the research room and in teachers' team. Let teachers consciously realize the important of mastering the information technology, therefore, they can renovate their knowledge structure and add the information technology in teaching content consciously.

University Literature Teaching in the Integration of Modern Information Technology Resources changed more artistic. Because there are so many information resources in the universities' literature teaching, it must be paid more attention to the artistry of the content in how to use, match and tailor these resources to satisfy the students. In the allocation of the pictures, sound and words, it should not only start from teaching aims, but also from aesthetic views to see. 
For example, the allocated ration of the pictures, sounds and words in teaching courseware that must have suitable length to avoid lose other aspects. At the same time, in the production of teaching courseware, it should balance the problem of color. Teachers should know some the common sense of allocated color, such as the cool tone, warm color, complementary color, contrast color, the theme color and background color. Students' eyes feel comfortable when the color is proper and don't produce the aesthetic fatigue. It can fit the atmosphere of teaching content. In the choice of sound, the dubbing should have great quality and the material of voice should choose the resource from authority organ which can be classic and representative. Therefore, only it combines the technology and artistry together, which can show the most teaching content for students absorbing in. It also can show the charm of the era of information technology education. It is the combination of science, technology and humanities cultivated manners.

University Literature Teaching in the Integration of Modern Information Technology Resources caring about details. With the coming of information age, and the ending of the era of print, the new technological media of the radio, television, films, videos and internet and so on are occupying and changing the living space of traditional literature. Because for most literary works that experience normal adaption, although it can extend the original works' vitality and can be accepted by more and more people, however after adaptation, the works have passed from text reading to digital appreciation, in literature content, style, literary production, media and literary reception have been completely heterogeneous. If teachers use this kind of resources do not control, the literature reading is easy to flow into the television appreciation. The unique aesthetic space of literary text will be abandoned completely. For some adaptation in the abnormal way, the remake, repetition, re-reading and resolving of the literature works, these adaption have already go bad and out of shape. The basic element and style in the original works have changed a lot. However, it doesn't be accepted when minorities dismantle and reverse the original works then adapt them. Therefore, for the huge network information resources in university literature teaching, teachers should make full use of them, and the same time they should pay more care in them. Teachers must do not misunderstand students and should lead students swim in the sea of literature by using the modern information resources.

\section{University Literature Teaching in the Integration of Modern Information Technology Resources changing the teaching mode}

University Literature Teaching in the Integration of Modern Information Technology Resources realizing distance education. University literature of distance education courses has broken through the limit of time and space of the traditional university literature education pattern, which promotes the popularization of literature and the general improvement in the humanities. Massachusetts institute was firstly to pull open the prelude of O.E.R in 2001, which planned to release all course materials of their college on the Internet. After that, many world famous universities, such as Yale, Harvard, Cambridge and Oxford added into the free dissemination of public classes. Apple Company opened the learning channel in 2006, and collected the course materials of many universities about Washington University, Duke University, Michigan University and Wisconsin University, so far the network curriculum has been broken through 100 million downloads. Among them, the literature courses about the Modern Poetry, American Novel since 1945, Literary Theory become a complete integration with modern information technology resources in these world first-class abroad universities in teaching reform. In April of 2003, our country ministry of education issued the "ministry of education about starting of higher school teaching quality and teaching reform project excellent course construction work notice”. It expounded the purpose of excellent course project construction: to promote the application of modern information technology in teaching, to share high quality teaching resources, to promote the professors standing on the platforms, to improve education quality of teaching. It made tens of 
millions of specialized personnel and a large number of creative talents. It also promoted the comprehensive strength and international competitiveness of Chinese higher education. Today, the excellent courses in many universities as a network form have established, perfected and matured in each university.

The University Literature Teaching in the Integration of Modern Information Technology Resources Changing the way of Teaching Practice. Literature teaching in universities that covers all literary phenomena in information age, so it is the subject that appears and develops together with these age and information. Therefore, it leads large of research literature resources to exist and to grow in internet world, such as the growing of network literature. Internet has more than 600 large libraries, more than 600 depositories and about 1 million information sources, so it leads the researchers in anywhere in the world to be research partners who can have a real-time online discussion and collaborative research to finish their researches. For teachers, they can enter the network at any time and get the latest dynamic condition information of science and technology, which can save the time and cost greatly in reviewing the literature. At the same time, the promptness and interactivity of Internet information transmission can let teachers update their reserved knowledge, analysis and handle the teaching materials according to the teaching goal. Teachers also can use the courseware or webpage form and through websites, blogs, BBS and other new ways to lead the students to learn professional knowledge. In literature teaching in university, students can use network resources to collect the authors, works, and the materials of writing background. Students put the collected information into sorting, processing, making documents. What's more, they choose the combination of personal and collaborative way to learn autonomously, and use information technology to complete the task. It cultivates the students' abilities to use the Internet to find and download information, the abilities to sort information and the abilities to analyze and put forward their own views. The subjectivity of students is showed in a larger degree, and it benefits to students' innovational spirit and solving problem ability. At the same time, teachers also play a leading role by various forms and various tools to help students to learn and to stimulate the students' study enthusiasm.

\section{Conclusion}

To sum up, the modern information technology resources apply into university literature teaching which has the incomparable virtues than the traditional teaching. The advantage causes teaching modes and teaching subjective identities diversely, as well as the teaching content changed of the times. How to find and develop more advantages of modern information resources, and how to combine them with university literature teaching, which still is research area needing the general educational workers to continuously explore and practice.

\section{References}

[1] Xu Peiyu: the Theory of Modern Science and Technology, (the Capital University of Economics and Trade Publications, Beijing 2002).

[2] Zhang Jiangnan, Wang Zhi: the Aesthetics in the Ara of Gastric Collaterals, (Shanghai Sanlian Press, Shanghai 2006).

[3] Desmond Keegan: Distance Education Theory Principle, (Central Radio and Television Rress, Beijing 1999).

[4] He Gaoda: Multimedia Aided Teaching of Theory and Application Research, (Wanren Press, Hong Kong 2001).

[5] JS.Wang: The culture of modern university, （Beijing university press, 2002）. 